\title{
Automated Water Treatment Alternative for Domestic use in Enugu State of Nigeria
}

\author{
A. I. Odo and C. R. Odo
}

\begin{abstract}
Many households in Enugu depend on water sourced from municipal water system for domestic use, especially for drinking purposes. Unfortunately, this source is not safe enough for drinking primarily due to poor water distribution network. As water travels from the Point of Treatment (POT) to the Point of Use (POU), it comes in contact with numerous contaminants via broken and rusty pipes. This study proposes a system that reduces or totally eliminates pollutants from domestic water at the point where it is used. Most of the naturally present pollutants (Bacteria, Viruses, Minerals, Heavy Metals, etc) are usually removed at the POT but results of tests carried out on water at various POUs within Enugu show that some levels of pollutants are present (Turbidity of 15 NTU, Colour of 25 units, Trihalomethane of $0.10 \mathrm{mg} / \mathrm{L}$, Odour $>3$ Threshold). These values are clearly outside the standards set by the World Health Organisation (WHO) for household and indeed drinking water [1]. By channelling water through a system of activated carbon filter, these pollutants are removed at POU. The system is made-up of a reservoir, filter and dispenser subsystems. Water enters the reservoir from the POT and from where the filter is fed. The output Water from the filter enters another reservoir from where it is dispensed. These processes of storage, treatment and dispensing are fully automated using a microcontroller chip to ensure efficiency and convenience. This study will be beneficial to the Ministry of water resources and the general public.
\end{abstract}

Index Terms-Control, automation, filtration, water, pollutant.

\section{INTRODUCTION}

Water is a common chemical substance that is essential for the survival of all known forms of life. In typical usage, water refers only to its liquid form or state, but the substance also has a solid state, ice, and a gaseous state, water vapor or steam. According to Wikipedia, water covers $71 \%$ of the Earth's surface [2]. With water covering more than half of the earth, one wonders why there is shortage of water for domestic use. This shortfall is as a result of pollutants. Clean, fresh drinking water is essential to humans and other life. However, some are of the view that by 2025 more than half of the world population will be facing water-based vulnerability, a situation regarded as water crisis by the United Nations [3].

Pollutants are present in varying proportions in water depending on the source. The Nigerian Standard for Drinking Water Quality has categorized pollutants into physical, organic and inorganic constituents, disinfectants and disinfectants by-products, radio-nuclides and

Manuscript received December 10, 2014; revised February 8, 2015.

The authors are with Enugu State University of Science and Technology, Nigeria (e-mail: ikechukwu.odo@esut.edu.ng, nasamail4u@yahoo.com). microbiological parameters [4]. However, at the point of use, most of these pollutants have been reduced leaving very fine particles and by-products of the disinfectants used. As simple as it may seem, these pollutants are not still safe for human consumption. Hence, requires extra filtration.

Filtration emerged in the last two decades as the forerunner of water treatment technology. Its innovative process is the only purification technique that can effectively remove Chlorine, which is the primary contaminant of municipally treated water. The filtration process utilizes a filter media through which water passes. Such filter media range from sand for older filters and solid block carbon or carbon media for newer filters. As the water passes through the stages of filtration (Activated Carbon as active element), contaminants are both physically and chemically blocked from passage through the filter media. Contaminants that are physically larger than the granules of the media will be blocked from passage while other undesirable elements in drinking water (such as chlorine and Volatile Organic Compounds) are encouraged to break their chemical bond with the water molecules and attach to the filter media [5]. The processes involved in the filtration are automated to ensure efficiency and convenience.

\section{A. Objectives of the Study}

The aim of this research is to:

1) Develop a system that removes pollutant from municipal water supply

2) Automate the treatment process, which includes filtration, storage and dispensing of clean water.

\section{B. Significance of the Study}

The study will be very beneficial to the inhabitants of Enugu. By effectively removing pollutants from water at the point of use, the health status of the community will greatly improve. With increasing health, the economic life of the people will also be enhanced.

Also, the Ministry of water resources will find the content of this study useful. From the findings of this research, the relevant authorities will be better informed to put the necessary machinery in place for effective water management.

\section{Methodology}

In this research, the Algorithmic State Machine (ASM) chart (Fig. 1) was used to represent the system's control sequence. In order to code this control sequence into the machine, the ASM chart was translated to a State Transition Table (Table I), from where a fully expanded table was realized (Table II). 


\section{A. Algorithm}

1) A power-up one shot pulse resets the control system to state 0 at start-up.

2) At state 0 , the control system displays ready while monitoring the level of water in the dispenser (DL) for either logic 0 or 1 . Logic 0 means that there is sufficient water in the dispenser. Logic 1 means that the dispenser tank is empty and should transfer control to state 1 .

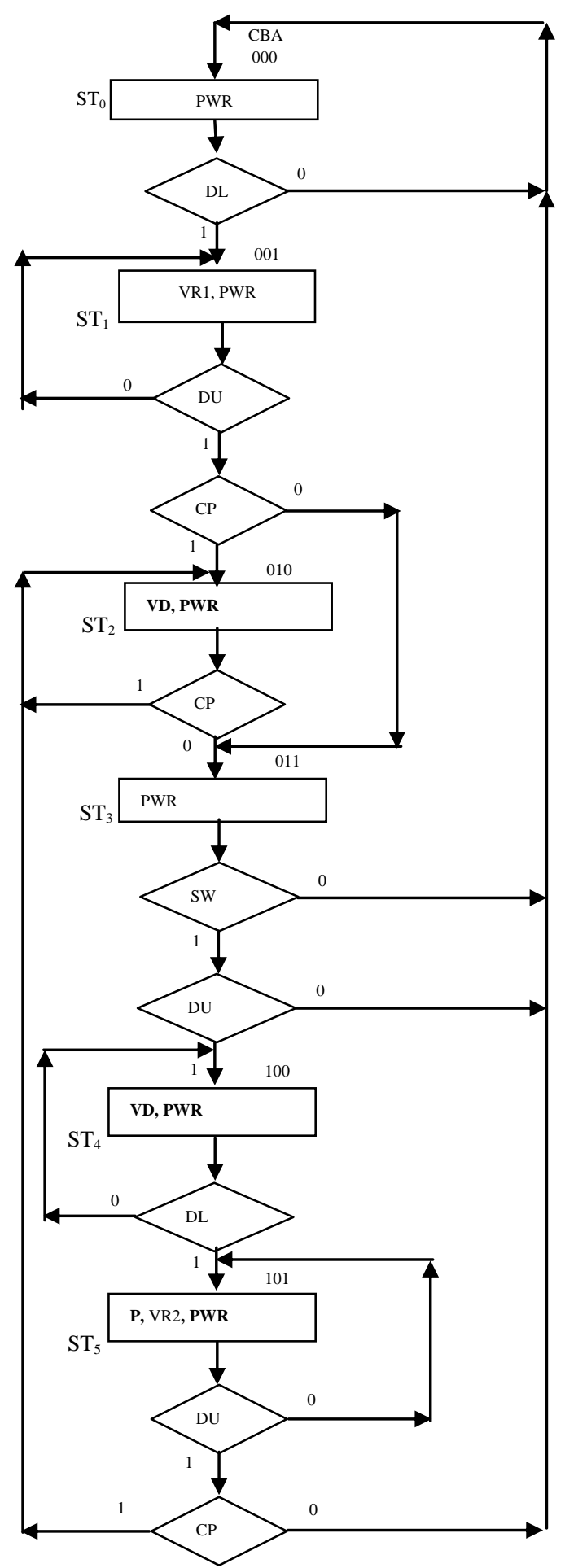

Fig. 1. ASM chart for the control system.

3) At state 1, the control system turns on valve (VR1) allowing water through the filter into the dispenser tank. The system status indicator must be $\mathrm{ON}$ at this stage as well. Also at this stage, the control monitors the upper threshold of water in the dispenser (DU). If $\mathrm{DU}$ is at logic 0 , it means there is provision for more water in the dispenser tank and treatment should continue. When DU changes state to logic 1, it means that the dispenser tank is full. This turns off VR1 while monitoring cup presence (CP). When a cup is present, $\mathrm{CP}$ is at logic 1. This transfers control to state 2 . However, if $\mathrm{CP}$ is at logic 0 at this stage, control is transferred to state 3 .

4) At state 2, the control system turns on the power indicator (PWR) and the dispenser valve (VD) to let water into a cup. While dispensing water, it goes back to monitor the cup presence for a change of state. If $\mathrm{CP}$ changes from logic 1 to 0 it means the cup has been withdrawn. This automatically turns off the dispenser valve and control if transferred to state 3 .

5) At state 3, only the PWR is a state output. The control at this stage monitors the recycle switch (SW). If there is need for recycle, SW is set to logic 1. Control will then proceed to monitor the upper threshold of water in dispenser tank (DU). If DU is at logic 1 it means we have a full tank and treatment can continue. Anything outside this combination will transfer control to state 0 .

6) At state 4, SW was pressed and the dispenser tank is also full. The dispenser valve (VD) is opened to empty the tank into a secondary reservoir. While that is going on, control monitors the lower threshold of water in the dispenser for logic 1, which means the tank is empty and ready for another round of treatment.

7) At state 5, DL is at logic 1. Control will turn on a secondary valve to allow water from the secondary reservoir through the filter and also energizes a pump to ensure a faster circulation of water. While treatment is in progress, control goes back to monitors the dispenser tank again. This time it is the upper threshold water level (DU) that is been monitored. Treatment will continue until DU is at logic 1 , which means the tank if full to capacity. When this is true, control begins to waits for the user to insert a cup. If there is a cup present, control is transferred to state 2. Otherwise, control starts from state 0 .

8) A power-up one shot pulse resets the control system to state 0 at start-up.

9) At state 0 , the control system displays ready while monitoring logic level from water level monitoring system (DL) of the dispenser for either logic 0 or 1 . Logic 0 means that there is sufficient water in the water dispenser. Logic 1 means that the dispenser tank is empty and this transfers control to state 1 .

10) At state 1, the control system turns on the valve (VR1) allowing water through the filter to the dispenser tank. The system status indicator must be $\mathrm{ON}$ at this stage as well. At this stage, the control monitors the upper threshold of water in the dispenser (DU). If DU is at $\operatorname{logic} 0$, it means there is provision for water in the dispenser tank and treatment should continue. When DU changes state to logic 1 , it means that the dispenser tank is full. This turns off the valve VR1 while monitoring cup presence (CP). When a cup is present, $\mathrm{CP}$ is at logic 1. This transfers control to state 2 . 
However, if $\mathrm{CP}$ is at logic 0 at this stage, control is transferred to state 3 .

11) At state 2, the control system turns on the power indicator (PWR) and the dispenser valve (VD) to dispense water into a cup. While dispensing water, it goes back to monitor the cup presence for a change of state. If $\mathrm{CP}$ changes from logic 1 to 0 it means the cup has been withdrawn. This automatically turns off the dispenser valve and control if transferred to state 3 .

12) At state 3, only the PWR is a state output. The control at this stage monitors the recycle switch (SW). If there is need for recycle, SW is at logic 1. Control will then proceed to monitor the upper threshold of water in dispenser tank (DU). If DU is at logic 1 it means we have a full tank and treatment can continue. Anything outside this combination will transfer control to state 0 .

13) At state 4, SW was pressed and the dispenser tank is also full. The dispenser valve (VD) is opened to empty the tank into a secondary reservoir. While that is going on, control monitors the lower threshold of water in the dispenser for logic 1 , which means the tank is empty and ready for another round of treatment.

14) At state 5, DL is at logic 1 . Control will turn on a secondary valve to allow water from the secondary reservoir through the filter and also energizes a pump to ensure a faster circulation of water. While treatment is in progress, control goes back to monitors the dispenser tank again. This time it is the upper threshold water level (DU) that is been monitored. Treatment will continue until DU is at logic 1 , which means the tank if full to capacity. When this is true, control begins to waits for the user to insert a cup. If there is a cup present, control is transferred to state 2. Otherwise, control starts from state 0 .

An ASM chart corresponding to the algorithm stated above is shown in Fig. 1.

\section{IMPLEMENTATION}

From Fig. 1, we see that there are six states (ST0, ST1, ST2, ST3, ST4 and ST5) with five state outputs, namely PWR, VR1, VR2, VD and PUMP. The logic levels of these state outputs are HIGH when the control system is at their respective states. The bit-pattern at the top right end of each box is the state code. The letters CBA above the state code signify that three flip-flops $\mathrm{C}, \mathrm{B}$ and $\mathrm{A}$ will represent the various states of the machine.

Each rectangular box in the ASM chart of Fig. 1 is a state box with their respective state names at the bottom left end. Here, we have ST0 for state 0, ST3 stands for state 3 and so on. Each decision box has one entry path and two exits. The value of the qualifier can either be 0 or 1 . The exact value of an input qualifier determines the exit path to follow. In Fig. 1, DL, DU, CP and SW are input qualifiers.

\section{A. The State Transition Table (STT)}

Every ASM chart has an equivalent tabular representation known as a State Transition Table (STT). An ASM chart can be fully described in terms of the link paths comprising it. A state machine as is represented by an ASM chart attempts to change state (i.e. transit from the present state to the next) when a clock pulse (or state time) occurs. A link path is a path followed from the present state either back to itself or to another state, when the clock pulse arrives. When there is an input qualifier between the present state and another, the logic level of the qualifier determines the next state the machine goes when the clock pulse arrives. If there is no qualifier between the present state and the next, the machine must unconditionally transit from the present state to the next adjacent state in the forward direction. The ASM chart of Fig. 1 has 15 link paths now represented by $L_{1}$ through $L_{15}$ in the STT. $L_{1}$ is the link path from state 0 to state 0 , when a clock pulse arrives and the qualifiers DL is at logic 0 . Also, $L_{2}$ is the link path from state 0 to state 1 , when the next clock pulse arrives and DL is at logic 1 and so on. The last link path $L_{15}$ concludes the control cycle as it transits from state 5 back to state 0 when a clock pulse arrives and $\mathrm{DU}=1$, while $\mathrm{CP}=0$. The details of the movement within ASM chart is represented here as Table I.

\begin{tabular}{|c|c|c|c|c|c|c|c|c|c|c|c|c|c|}
\hline \multirow{3}{*}{$\begin{array}{c}\text { LINK } \\
\text { PATH } \\
\text { L }\end{array}$} & \multicolumn{13}{|c|}{ TABLE I: STATE TRANSITION TABLE (STT) } \\
\hline & \multicolumn{4}{|c|}{ QUALIFIERS } & \multicolumn{2}{|c|}{$\begin{array}{c}\text { PRESENT STATE } \\
\text { NAME } \\
\text { CODE }\end{array}$} & \multicolumn{2}{|c|}{ NEXT STATE } & \multicolumn{5}{|c|}{ STATE OUTPUTS } \\
\hline & $\begin{array}{l}\mathrm{D} \\
\mathrm{U}\end{array}$ & $\begin{array}{l}\text { C } \\
P\end{array}$ & $\begin{array}{l}\mathrm{S} \\
\mathrm{W}\end{array}$ & $\begin{array}{l}\text { D } \\
\text { L }\end{array}$ & NAME & $\mathrm{CBA}$ & NAME & $C^{\prime} B^{\prime} A^{\prime}$ & $\begin{array}{l}\mathrm{P} \\
\mathrm{W} \\
\mathrm{R}\end{array}$ & $\begin{array}{l}\mathrm{V} \\
\mathrm{R} \\
1\end{array}$ & $\begin{array}{l}\text { V } \\
D\end{array}$ & $\mathrm{P}$ & $\begin{array}{l}\mathrm{V} \\
\mathrm{R} \\
2\end{array}$ \\
\hline L1 & $\mathrm{x}$ & $\mathrm{x}$ & $\mathrm{x}$ & 0 & ST0 & 000 & ST0 & 000 & 1 & 0 & 0 & 0 & 0 \\
\hline L2 & $\mathrm{x}$ & $\mathrm{x}$ & $\mathrm{x}$ & 1 & ST0 & 000 & ST1 & 001 & 1 & 0 & 0 & 0 & 0 \\
\hline L3 & 0 & $\mathrm{x}$ & $\mathrm{x}$ & $\mathrm{x}$ & ST1 & 001 & ST1 & 001 & 1 & 1 & 0 & 0 & 0 \\
\hline L4 & 1 & 1 & $\mathrm{x}$ & $\mathrm{x}$ & ST1 & 001 & ST2 & 010 & 1 & 1 & 0 & 0 & 0 \\
\hline L5 & 1 & 0 & $\mathrm{x}$ & $\mathrm{x}$ & ST1 & 001 & ST3 & 011 & 1 & 1 & 0 & 0 & 0 \\
\hline L6 & $\mathrm{x}$ & 1 & $\mathrm{x}$ & $\mathrm{x}$ & ST2 & 010 & ST2 & 010 & 1 & 0 & 1 & 0 & 0 \\
\hline L7 & $\mathrm{x}$ & 0 & $\mathrm{x}$ & $\mathrm{x}$ & ST2 & 010 & ST3 & 011 & 1 & 0 & 1 & 0 & 0 \\
\hline L8 & $\mathrm{x}$ & $\mathrm{x}$ & 0 & $\mathrm{x}$ & ST3 & 011 & ST0 & 000 & 1 & 0 & 0 & 0 & 0 \\
\hline L9 & 0 & $\mathrm{x}$ & 1 & $\mathrm{x}$ & ST3 & 011 & ST0 & 000 & 1 & 0 & 0 & 0 & 0 \\
\hline L10 & 1 & $\mathrm{x}$ & 1 & $\mathrm{x}$ & ST3 & 011 & ST4 & 100 & 1 & 0 & 0 & 0 & 0 \\
\hline L11 & $\mathrm{x}$ & $\mathrm{x}$ & $\mathrm{x}$ & 0 & ST 4 & 100 & ST4 & 100 & 1 & 0 & 1 & 0 & 0 \\
\hline L12 & $x$ & $\mathrm{x}$ & $\mathrm{x}$ & 1 & ST4 & 100 & ST5 & 101 & 1 & 0 & 1 & 0 & 0 \\
\hline L13 & 0 & $\mathrm{x}$ & $\mathrm{x}$ & $\mathrm{x}$ & ST5 & 101 & ST5 & 101 & 1 & 0 & 0 & 1 & 1 \\
\hline L14 & 1 & 0 & $\mathrm{x}$ & $\mathrm{x}$ & ST5 & 101 & ST0 & 000 & 1 & 0 & 0 & 1 & 1 \\
\hline L15 & 1 & 1 & $\mathrm{x}$ & $\mathrm{x}$ & ST5 & 101 & ST2 & 010 & 1 & 0 & 0 & 1 & 1 \\
\hline
\end{tabular}

In the State Transition Table (Table I) above, which is the tabular representation of the information contained in the ASM chart of Fig. 1, every data row corresponds to a link path. Just as 15 link paths described the ASM chart, so also does the STT have 15 data rows, one row per link path. It follows therefore, that a state machine is fully described by the information contained in all the link paths comprising it [6].

In Table I, a number of "Don't Care" conditions appear (x) under the column headed by the input qualifiers. This means that for there to be a transition along a link path, the condition of this qualifier has no effect whatsoever. Hence the qualifier could be logic 0 or 1 yet will have no meaning at that instance.

\section{B. Fully Expanded State Transition Table}

To program the EEPROM, one needs to define all address inputs including the qualifiers as either 0 or 1 and not "Don't Cares" as in Table I. A State Transition Table (STT) is said to be fully expanded when all the Don't Care instances are given all possible combinations of logic values, leading to new rows in the STT [7]. Looking at Table I, the link paths can be grouped into two. Group 1 comprising L1, $L_{2}, L_{3}, L_{6}, L_{7}, L_{8}, L_{11}, L_{12}$ and $L_{13}$ have 3 don't care qualifiers each. For these links to be fully addressable there will be $2^{3}$ $=8$ possible combinations of addresses per link path (i.e. $8 \times$ 9 link paths $=72$ address lines). Group 2 made up of links $L_{4}$, $L_{5}, L_{9}, L_{10}, L_{14}$, and $L_{15}$ have 2 Don't Cares per link path. The number of possible combinations of logic values per 
link path is equal to 4 i.e. $2^{2}$. Therefore, group 2 will have 4 $\times 6=24$ address lines. This gives a total of 96 address lines for all the input combinations required in this design.

In this design, the input qualifiers DU, CP, SW and DL with the present state code CBA form the ADDRESS pattern for the ROM as shown under the ADDRESS column of Table II. Also, the next state code C'B'A' with the state outputs form the memory content as shown under the CONTENT column in Table II. Table II is the result of expanding $L_{1}$ of Table I. The fully expanded state transition tables for $L_{2}$ through $L_{15}$ are not included in this report for want of space.

TABLE II: FULLy EXPANDED STATE TRANSITION TABLE - LINK 1

\begin{tabular}{|c|c|c|c|c|c|c|c|c|c|c|c|c|c|c|}
\hline 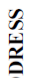 & & JAL & FIER & & & $\begin{array}{l}\text { ENT } \\
\text { TE }\end{array}$ & NEX & STATE & & ATI & OU & PUTS & & 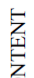 \\
\hline 屏 & $\begin{array}{l}\text { D } \\
\text { U }\end{array}$ & $\begin{array}{l}\text { C } \\
\text { P }\end{array}$ & $\begin{array}{l}\text { s } \\
\text { w }\end{array}$ & $\begin{array}{l}\text { D } \\
\text { L }\end{array}$ & $\sum_{\Sigma}^{\omega}$ & CBA & $\sum_{\frac{L}{z}}^{\mathrm{U}}$ & $C^{\prime} B^{\prime} A^{\prime}$ & $\begin{array}{l}\mathbf{P} \\
\mathbf{W} \\
\mathbf{R}\end{array}$ & $\begin{array}{l}\mathrm{V} \\
\mathrm{R} \\
\mathbf{1}\end{array}$ & $\begin{array}{l}\text { V } \\
\text { D }\end{array}$ & $\begin{array}{l}P \\
U \\
M \\
P\end{array}$ & $\begin{array}{l}\mathrm{V} \\
\mathrm{R} \\
\mathbf{2}\end{array}$ & $\begin{array}{l}\text { 离 } \\
\text { 至 }\end{array}$ \\
\hline 00 & 0 & 0 & 0 & 0 & ST0 & 000 & ST0 & 000 & 1 & 0 & 0 & 0 & 0 & 10 \\
\hline 10 & 0 & 0 & 1 & 0 & ST0 & 000 & ST0 & 000 & 1 & 0 & 0 & 0 & 0 & 10 \\
\hline 20 & 0 & 1 & 0 & 0 & ST0 & 000 & ST0 & 000 & 1 & 0 & 0 & 0 & 0 & 10 \\
\hline 30 & 0 & 1 & 1 & 0 & ST0 & 000 & ST0 & 000 & 1 & 0 & 0 & 0 & 0 & 10 \\
\hline 40 & 1 & 0 & 0 & 0 & ST0 & 000 & ST0 & 000 & 1 & 0 & 0 & 0 & 0 & 10 \\
\hline 50 & 1 & 0 & 1 & 0 & ST0 & 000 & ST0 & 000 & 1 & 0 & 0 & 0 & 0 & 10 \\
\hline 60 & 1 & 1 & 0 & 0 & ST0 & 000 & ST0 & 000 & 1 & 0 & 0 & 0 & 0 & 10 \\
\hline 70 & 1 & 1 & 1 & 0 & ST0 & 000 & ST0 & 000 & 1 & 0 & 0 & 0 & 0 & 10 \\
\hline
\end{tabular}

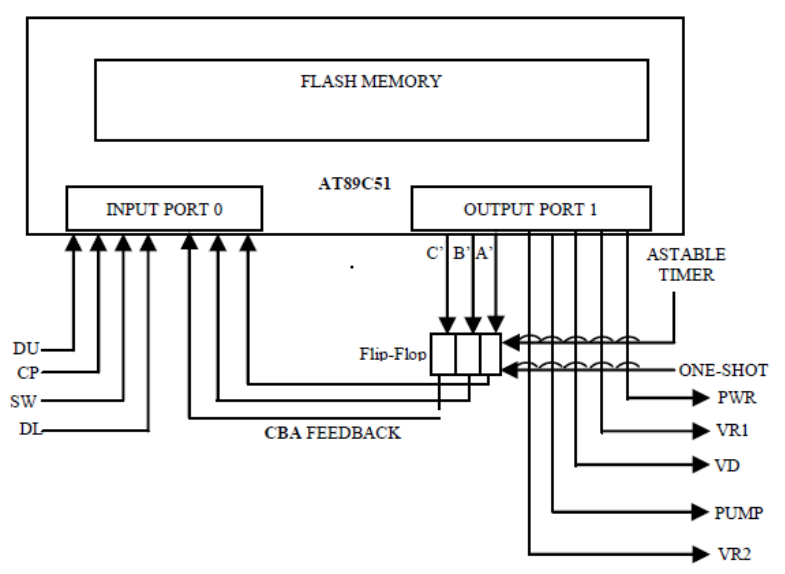

Fig. 2. Control system block diagram showing the input and output.

The implementation of Table II uses the Link Path Addressable ROM Structure. The address inputs to the address decoder section of the system will be made via an input port of the microcontroller, which is then used to locate the corresponding NEXT STATE and STATE OUTPUTS as shown in Fig. 2 below. When a clock pulse arrives, the NEXT STATE pattern becomes the present state pattern. This joins the input qualifiers to make-up the address input of the microcontroller. A power-up-one-shot applied to the D-type Flip-Flop that feedback the NEXT STATE as the PRESENT STATE when a clock pulse occurs This also initializes the system to the starting state where the state code $\mathrm{CBA}=000$ (state 0 ).

\section{SUMMARY AND RECOMMENDATIONS}

The automated domestic water treatment alternative has been described using the algorithmic state machine (ASM) chart and implemented by translating the ASM chart into a fully expanded state transition table. This table contains all the control logic for the system, including the input and output commands. The content of this table was coded into a microcontroller that drives the system.

The active purification element in this study was a column of Activated Carbons. It was found that in addition to filtering tiny particles from the water at POUs, it also eliminated other pollutants like colour, turbidity and byproducts of disinfectants. Table III shows the before and after states of water samples tested with the system. The results, especially as it concerns the Trihalomethane were very satisfactory and within the boundary set be WHO for drinking water standard.

It is therefore recommended that the Ministry of water resources and indeed all stakeholders in public utilities should adopt this system for the purification of household water. There is a common saying that water is life but certainly not bad water. The use of this system will greatly improve the health of the inhabitants of Enugu and by extension increase their economic life.

\section{A. Block Diagram Overview of the System}

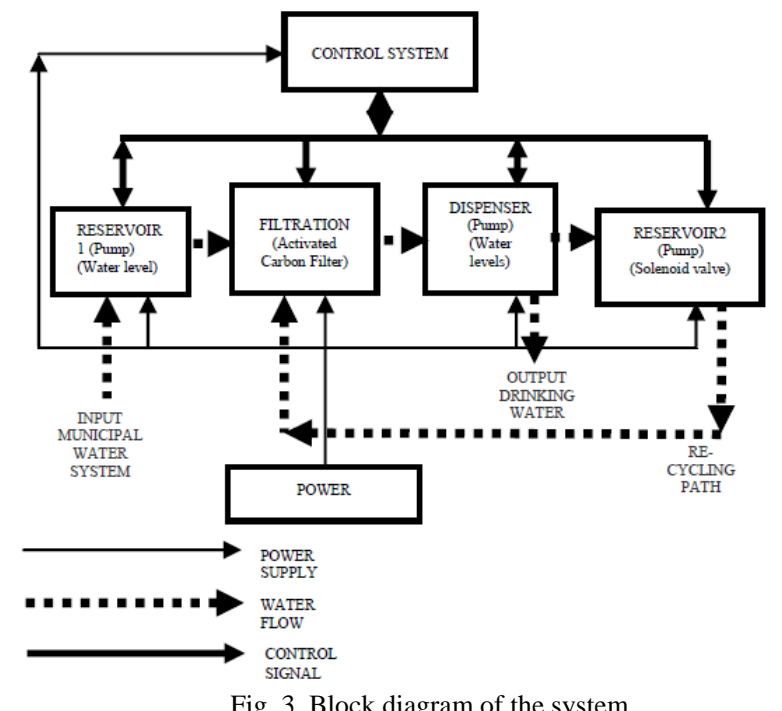

Fig. 3. Block diagram of the system.

\begin{tabular}{lllll} 
Test Data & \multicolumn{4}{c}{ TABLE III: QUALITY TEST } \\
& Unit & Before Test & Treatment 1 & Treatment 2 \\
& & & & \\
\hline Odour & - & Objectionable & Unobjectionable & Unobjectionable \\
Colour & TCU & 35 & 17 & 12 \\
Taste & - & Objectionable & Unobjectionable & Unobjectionable \\
Turbidity & NTU & 25 & 10 & 5 \\
Trihalomethane & $\mathrm{mg} / \mathrm{L}$ & 0.01 & 0.001 & 0.001 \\
\hline
\end{tabular}

\section{REFERENCES}

[1] R. L. Caldron and E. W. Mood, "Bacteria colonizing point-of-use, granular activated carbon filters and their Relationship to human health," Health Effects Research Lab, p. 108, 1987.

[2] Wikipedia "CIA - The world factbook" Central Intelligence Agency. [Online]. Available: http://www. en.wikipedia.org/wiki/Water

[3] S. G. Ramandeep, K. Vinod, N. Ashutosh, S. Raman, and B. Vikram, (2012). Impact of Pollutants and New Promising Techniques in Purification Process. [Online]. Available: http://www.indiaenvironmentportal.org.in/files/file/Purificati\%20Proc ess.pdf

[4] Nigerian Industrial Standard (NIS), vol. 554, 2007

[5] N. Mesner, "How to protect your well water," Utah State University Water Quality Extension, Utah State University, pp. 56-59, 2005. 
[6] H. C. Inyiama and C. C. Okezie "Designing microcontroller-based universal process control system," International Journal of Electrical and Tele. Systems Research, vol. 2, no. 2, p. 11, Nov. 2007.

[7] K. A. Akpado, H. C. Inyiama, A. Ejiofor, and H. Ejiofor. Linked State Machine Approach to Industrial Process Control Systems Design. [Online]. Available: http://www.ijareeie.com/upload/2013/november/2_Linked.pdf.

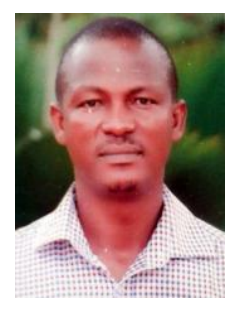

A. I. Odo was born in Nigeria, in 1975 . He received his B.Eng degree in computer science and engineering from Enugu State University of Science and Technology, Enugu, Nigeria in 2001, He received his M.Eng in electronic and computer engineering from Nnamdi Azikiwe University Awka, Anambra State of Nigeria in 2009. Currently he is a $\mathrm{PhD}$ student at Nnamdi Azikiwe University, Awka-Anambra State, Nigeria. He is currently a staff member of Enugu State University of Science and Technology (Lecturering in the Department of Computer Engineering). His publications include Fundamentals of Operations Research (Book 2010), Science and Technology Education: "Strategic tool for human capital development in nigeria," Journal of Nigeria Research Association-NERA, vol. 15, pp. 132136, 2010; "Empowering the nigerian woman through teacher education," Journal of Reflective Thinking, vol. 2, no. 1, pp. 269-277, 2013. His research interests include are industrial systems and automation.

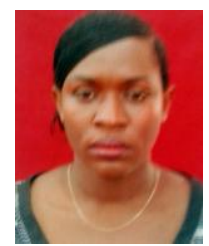

C. R. Odo was born in Nigeria, in 1978. She received her B.Sc degree in computer science education from University of Nigeria, Nsukka, Enugu, Nigeria in 2005. Currently she is a student at master level in computer science education at Enugu state University of Science and Technology, Enugu State, Nigeria.

She is currently working with Enugu State College of Education Technical as a lecturer. Her publication include Fundamentals of Operations Research (Book 2010), Science and Technology Education: "Strategic tool for human capital development in Nigeria," Journal of Nigeria Research Association-NERA, vol. 15, no. 1, pp. 132-136, 2010; "Electronic waste management practices of sole proprietors in Enugu urban," Nigerian Journal of Health Educators, vol 16, no. 1, pp. 121-133, 2012. Currently, Her research interest is in computer software. 